\title{
Effect of chewing gum on the postoperative recovery of gastrointestinal function after gynaecological laparoscopic surgery
}

\author{
Binti Bhatiyani, Pandeeswari*, Dolly Bhasani, Shrikant Dhumale
}

Department of Obstetrics and Gynecology, ESIPGIMSR, Andheri East, Mumbai, Maharashtra, India

Received: 09 December 2017

Accepted: 08 January 2018

\section{*Correspondence:}

Dr. Pandeeswari,

E-mail: pandeeswaribalakrishnan@gmail.com

Copyright: () the author(s), publisher and licensee Medip Academy. This is an open-access article distributed under the terms of the Creative Commons Attribution Non-Commercial License, which permits unrestricted non-commercial use, distribution, and reproduction in any medium, provided the original work is properly cited.

\begin{abstract}
Background: The incidence of postoperative ileus (POI) after gynaecological surgery is 10-15\%. Chewing gum following general surgery improves outcomes, including early flatus, early bowel sounds, and shortening of the hospitalisation period. This study aims to investigate the effect of postoperative gum chewing on bowel motility after laparoscopic gynaecologic surgery.

Methods: 101 women who underwent laparoscopic surgery for benign gynaecological conditions under general anaesthesia were recruited. 50 patients received sugar free chewing gum post operatively and the outcomes were compared with the control group. The study's primary end points were the time to first regular bowel sounds and time to passage of flatus after surgery. Secondary end points were the time to first defecation, patient satisfaction, and potential side effects of postoperative gum chewing.

Results: We found a significantly shorter interval between surgery and passage of flatus in the intervention group (median 10 hours compared with 13 hours $\mathrm{p}=0.0151$ ) and a significantly higher rate of regular bowel sounds 3 hours ( $74 \%$ compared with $45 \% ; \mathrm{p}=0.003$ ) and 5 hours after surgery (91\% compared with $78 \% ; \mathrm{p}=0.01$ ). There was no significant difference in time to first defecation between groups (median 18 hours compared with 20 hours; $\mathrm{p}=0.222$ ). Conclusions: Gum chewing seems to have beneficial effects on bowel motility when used in postoperative care after minimally invasive surgery. Gum chewing should be recommended to patients after gynaecological laparoscopic surgery
\end{abstract}

Keywords: Chewing gum, Gastrointestinal function, Postoperative ileus

\section{INTRODUCTION}

Post-operative gastrointestinal dysfunction especially postoperative ileus is a major contributing factor in discomfort and prolonged hospital stay after surgery. Gastrointestinal dysfunction can cause the accumulation of secretions and gas, resulting in nausea, vomiting, abdominal distension and pain. Gum chewing has been reported to stimulate bowel motility after open abdominal surgery such as caesarean section, liver resection, colorectal surgery and after laparoscopic surgery. ${ }^{1-7}$ Gum chewing mimics food intake and is considered a kind of sham feeding. The physiological mechanism for the enhanced recovery of bowel motility by gum chewing is assumed to be the activation of the cephalic vagal pathway, which is stimulating intestinal myoelectrical activity in an attempt to counteract activation of the gastrointestinal $\mu$ opioid receptor. ${ }^{8}$

Chewing gum is a form of sham feeding to stimulate the acceleration of gut function after abdominal surgery. ${ }^{9}$ It also increases the plasma concentration of the peptide hormone gastrin, the neuropeptide neurotensin, and that of pancreatic polypeptide. ${ }^{10}$ In addition sham feeding 
enhances duodenal alkaline secretion. Therefore, gum chewing enhances bowel motility directly by cephalicvagal pathway activation and indirectly by triggering the release of gastrointestinal hormones and increasing the secretion of saliva and pancreatic juice. ${ }^{11}$ The severity of gastrointestinal dysfunction depends on the extent of surgical trauma and bowel manipulation. Surgical trauma causes a decrease in bowel motility through activation of sympathetic activity. Associated with the stress response is the release of inflammatory mediators such as vasoactive intestinal peptide, substance $\mathrm{P}$ and nitric oxide, which contributes to postoperative gastrointestinal dysfunction and ileus. ${ }^{12}$ The aim of this study was to investigate the effect of gum chewing on bowel motility after minimally invasive Gynaecological surgery without involvement of bowel.

The efficacy of chewing gum has been fully elucidated in the intestinal function recovery in patients after colorectal surgery and it can provide various benefits. Chewing gum after elective intestinal resection has been associated with various improved outcomes including early flatus, early bowel sounds and shorter lengths of hospitalisation. ${ }^{13,14}$ There are many non-pharmacologic treatment such as early enteral nutrition, early mobilization, laparoscopic surgery, psychological preoperative preparation among them the use of chewing gum also has emerged as a new, simple, readily available and cost effective modality for decreasing POI. ${ }^{15}$

\section{METHODS}

This was prospective trial performed at tertiary care centre. The study was approved by local institutional ethics committee. All women who underwent laparoscopic surgery for benign gynaecologic conditions under general anaesthesia at our institution between Jan 2016 and Dec 2017 were invited to participate in this trial. Women between age 18 and 80 years were eligible for study inclusion. Patients with loose teeth and chronic obstipation were excluded. If the operation time was more than 3 hours or a laparotomy had to be performed; patients were excluded from further analysis.

Eligible patients were invited to participate on the day of surgery by one member of the research team. The trial was explained and written informed consent was obtained. At this point, demographic data were noted. All patients were asked to notify nursing or medical staff when first passage of flatus occurred. Patients in the chewing gum group started gum chewing every 2 hours for 15 minutes, beginning 2 hours postoperatively. Numbers of chewing gums used were counted. Patients stopped gum chewing after first passage of flatus and returned the cardboard. Patients assigned to the control group did not chew gum and standard postoperative care was provided. All patients were allowed to start oral intake of fluids and soft and solid foods when bowel was first noticed, at the earliest 6 hours postoperatively.
The bowel sounds were checked on each patient using standard stethoscope every 2 hours beginning 3 hours postoperatively until first bowel sounds were noticed. All operations were performed under general anaesthesia. For postoperative analgesia, we used diclofenac and acetaminofen. If the patient did not achieve adequate relief, she was given injection Tramadol intramuscularly according to unit protocol. Pain was assessed by a visual analogue scale

Participants were followed until the fourth postoperative day. At the day of discharge, patient's satisfaction concerning postoperative gum chewing was assessed using visual analogue scale. Patients in intervention group were asked to rate treatment satisfaction. The lowest score was one reflecting maximal dissatisfaction and the highest score was 10 reflecting maximal satisfaction.

The study's primary end points were time to first regular postoperative borborygmus and time to first passage of flatus. The time at the end of the operation was defined as the 0 hour. Secondary end points were time of operation to first defecation, patient satisfaction concerning postoperative gum chewing, potential side effects of postoperative gum chewing.

\section{RESULTS}

101 patients were included in this trial. The demographic characteristics are included in Table 1 and the indications for surgery are listed in Table 3. Patients groups were comparable and did not differ with respect to body mass index, age, duration of surgery, or length of hospitalization.

Table 1: Characteristics of women chewing gum (intervention group) and women not chewing gum (control group).

\begin{tabular}{|llll|}
\hline Characteristic & $\begin{array}{l}\text { Intervention } \\
\text { group } \\
(\mathbf{n = 5 0 )}\end{array}$ & $\begin{array}{l}\text { control } \\
\text { group } \\
(\mathbf{n = 5 1 )}\end{array}$ & $\mathrm{p}^{*}$ \\
\hline Age (years) & $30(24-56)$ & $32(21-58)$ & 0.28 \\
\hline $\begin{array}{l}\text { Body mass } \\
\text { index }\end{array}$ & $\begin{array}{l}23.1 \\
(17.8-36.6)\end{array}$ & $\begin{array}{l}23.6 \\
(16.1-38.2)\end{array}$ & 0.68 \\
\hline $\begin{array}{l}\text { Duration of } \\
\text { surgery }\end{array}$ & $\begin{array}{l}90 \\
(30-200)\end{array}$ & $\begin{array}{l}120 \\
(30-228)\end{array}$ & 0.004 \\
\hline $\begin{array}{l}\text { Length of } \\
\text { hospitalization }\end{array}$ & 3 & 3 & 0.96 \\
\hline
\end{tabular}

It was found that gum chewing was well tolerated, and all patients included in final analysis completed their course of gum chewing until passage of first flatus. No adverse events such as choking, or aspiration were observed in relation to gum chewing. None of the participants required reoperation or readmission after hospital discharge or blood transfusion. 
We found a significantly shorter interval between surgery and passage of flatus in this intervention group compared with the control group (median 10 hours compared with 13 hours $\mathrm{p}=0.0151$ ) and a significantly higher rate of regular bowel sounds 3 hours $(74 \%$ compared with 45\%; $\mathrm{p}=0.003)$ and 5 hours $(91 \%$ compared with $78 \%$; $=0.01$ ) after surgery Table 2 .

Table 2: Comparisons of outcome parameters between groups.

\begin{tabular}{|llll|}
\hline & $\begin{array}{l}\text { Intervention } \\
\text { group } \\
(\mathrm{n}=50)\end{array}$ & $\begin{array}{l}\text { Control } \\
\text { group } \\
(\mathrm{n}=51)\end{array}$ & p* \\
\hline $\begin{array}{l}\text { First passage of } \\
\text { flatus }\end{array}$ & $10(2.3-26)$ & $13(2.6-28)$ & 0.0151 \\
$\begin{array}{l}\text { Bowel sounds } \\
\text { heard after 3h }\end{array}$ & $37(74 \%)$ & $23(45 \%)$ & 0.003 \\
\hline $\begin{array}{l}\text { Bowel sounds } \\
\text { heard after 5h }\end{array}$ & $45(90 \%)$ & $\begin{array}{l}35 \\
(68.6 \%)\end{array}$ & 0.008 \\
\hline $\begin{array}{l}\text { Bowel sounds } \\
\text { heard after 7h }\end{array}$ & $49(98 \%)$ & $45(90 \%)$ & 0.05 \\
\hline $\begin{array}{l}\text { First } \\
\text { post-operative } \\
\text { patient } \\
\text { mobilization }\end{array}$ & $\begin{array}{l}163 \text { minutes } \\
(75-530)\end{array}$ & $\begin{array}{l}167 \text { minutes } \\
(78-277)\end{array}$ & 0.73 \\
\hline First defecation & $\begin{array}{l}18 \text { hours } \\
(8-56)\end{array}$ & $\begin{array}{l}20 \text { hours } \\
(8.5-60)\end{array}$ & 0.222 \\
\hline
\end{tabular}

Data are median (range) or $\mathrm{n}(\%)$ unless otherwise specified; *Mann-Whitney U test or $\mathrm{X}^{2}$ test

Fewer opioid analgesics were administered to patients allocated to the intervention group. There was no significant difference in time to first defecation between groups (median 18 hours compared with 20 hours; $p$ $=0.222$ ) there was no difference in the time to mobilisation after surgery.

It is current practice at our institution to mobilize patients as soon as possible after surgery. Patients in this trial were mobilized on average 3 hours postoperatively. This might also have had a positive effect on return of regular bowel motility. Nevertheless, fast-track mobilization alone has not been shown to have a positive effect on bowel motility in previous studies. ${ }^{16}$

Statistical analysis was conducted. Continuous variables are summarized as mean ( \pm standard deviation) or median (Range) and categorical data presented as percentages. Chi square test, Fischer's exact test, Mann-Whitney U test, and binomial test were used accordingly. $\mathrm{P} \leq 0.05$ was considered statistically significant.

\section{DISCUSSION}

The results of the present study have indicated that gum chewing after laparoscopic gynecologic surgery can significantly promote the intestinal function recovery by accelerating the time to first passage of flatus and first bowel sounds. With increasing pressure on limited medical resources and the need to improve patient satisfaction worldwide, strategies to reduce the postoperative sequelae and hospitalization length are of significant importance.

This study shows that postoperative gum chewing promotes bowel motility. First passage of flatus was significantly accelerated in the gum chewing group and a significantly higher rate of regular bowel sounds after 3 hours and 5 hours was observed (Table 3 ).

Table 3: Type of surgery.

\begin{tabular}{|ll|c|}
\hline $\begin{array}{l}\text { Type of surgery } \\
\text { Total laparoscopic }\end{array}$ & $\begin{array}{l}\text { Intervention } \\
\text { group }(\mathrm{n}=50)\end{array}$ & $\begin{array}{c}\text { control group } \\
(\mathrm{n}=51)\end{array}$ \\
\hline $\begin{array}{l}\text { Hysterectomy } \\
\text { MTP with TL }\end{array}$ & $20(12 \%)$ & $4(7.8 \%)$ \\
\hline $\begin{array}{l}\text { Unilateral } \\
\text { salphingo- } \\
\text { oophorectomy } \\
\text { or salphingectomy }\end{array}$ & $7(14 \%)$ & $18(35.2 \%)$ \\
\hline $\begin{array}{l}\text { Diagnostic } \\
\text { Hysterolaparoscopy }\end{array}$ & $17(34 \%)$ & $19(37.2 \%)$ \\
\hline
\end{tabular}

These findings are clinically relevant and important for minimally invasive gynecologic surgeons, because besides the beneficial effect of postoperative gum chewing, they place the patients at small risk for postoperative ileus with generally fast recovery of normal bowel motility and passage of first flatus. Postoperative gum chewing enhances return of regular bowel motility after surgery. This might be achieved directly by gum chewing or indirectly by reducing pain and the quantity of postoperative opiate use. Gum chewing is an inexpensive and physiologic intervention, which appears to be reasonably safe in the postoperative patients we studied. It was well tolerated in the early postoperative period and resulted in high patient satisfaction. Gum chewing seems to have beneficial effects when used as an adjunct treatment in postoperative care. Therefore, postoperative gum chewing should be recommended to patients after gynaecologic laparoscopic surgery.

Heinrich $\mathrm{H}$ et al performed a randomized controlled trial to investigate the effect of postoperative gum chewing on bowel motility after laparoscopic gynecologic surgery. The result showed a significantly shorter interval between surgery and passage of first flatus in the intervention group compared with the control group (median 6.2 hours versus 8.1 hours) and a significantly higher rate of regular bowel sounds 3 hours (76\% versus $47 \%$ ) and 5 hours (91\% versus $78 \%$ ) after surgery. These results confirmed that gum chewing seems to have beneficial effects on bowel motility when used as an adjunct treatment in postoperative care after minimally invasive surgery. ${ }^{8}$

The findings of Ahmed AS study review suggest that chewing gum may be effective for shortening the time to first flatus, time to first bowel sounds and time to first 
defecation following caesarean sections. In addition, it reduces the requirement for enemas and antiemetics. The use of chewing gum in women undergoing caesarean sections also reduces the risk of POI, but does not affect the length of hospitalisation. ${ }^{9}$

Nimrata et al concluded that use of chewing gum in the postoperative period is a safe and cheap method to stimulate bowel motility and reduce the postoperative ileus after abdominal surgery. ${ }^{17}$

\section{CONCLUSION}

Postoperative gum chewing enhances return of regular bowel motility after surgery. This might be achieved directly by gum chewing or indirectly by reducing pain and the quantity of postoperative opiate use. It is an inexpensive and physiologic intervention, which appears to be reasonably safe in the postoperative patients. It was well tolerated and resulted in high patient satisfaction. Therefore, postoperative gum chewing should be recommended to patients after gynecologic laparoscopic surgery.

\section{ACKNOWLEDGMENTS}

Authors would like to acknowledge their Dean Dr. Meenakshi Mathur for her support and encouragement.

Funding: No funding sources

Conflict of interest: None declared

Ethical approval: The study was approved by the Institutional Ethics Committee

\section{REFERENCES}

1. Abd-El-Maeboud KH, Ibrahim MI, Shalaby DA, Fikry MF. Gum chewing stimulates early return of bowel motility after caesarean section. BJOG 2009;116:1334-9.

2. Kafali H, Duvan CI, Gözdemir E, Simavli S, Onaran $\mathrm{Y}$, Keskin E. Influence of gum chewing on postoperative bowel activity after cesarean section. Gynecol Obstet Invest. 2010;69:84-7.

3. Jang SY, Ju EY, Kim DE, Kim JH, Kim YH, Son M, et al. First flatus time and xerostomia associated with gum-chewing after liver resection. J Clin Nurs. 2012;21:2188-92.

4. Schuster R, Grewal N, Greaney GC, Waxman K. Chewing reduces ileus after elective open sigmoid colectomy. Arch Surg. 2006;141:174-6.

5. Vásquez W, Hernández AV, Garcia-Sabrido JL. Is gum chewing useful for ileus after elective colorectal surgery? A systematic review and meta-analysis of randomized clinical trials. J Gastrointest Surg. 2009;13:649-56.
6. Asao T, Kuwano H, Nakamura JI, Morinaga N, Hirayama I, Ide M. Gum chewing enhances early recovery from postoperative ileus after laparoscopic colectomy. J Am Coll Surg. 2002;195:30-2.

7. Choi H, Kang SH, Yoon DK, Kang SG, Ko HY, Moon du G, et al. Chewing gum has a stimulatory effect on bowel motility in patients after open or robotic radical cystectomy for bladder cancer: a prospective randomized comparative study. Urol. 2011;77:884-90.

8. Husslein H, Franz M, Gutschi M, Worda C, Polterauer S, Leipold H. Postoperative gum chewing after gynecologic laparoscopic surgery. Obstet Gynecol. 2013122:85-90.

9. Craciunas L, Sajid MS, Ahmed AS. Chewing gum in preventing postoperative ileus in women undergoing caesarean section: a systematic review and metaanalysis of randomized controlled trials. BJOG. 2014;121:793-800.

10. Park SY, Chung M. Can gum chewing reduce postoperative ileus after open abdominal surgery. Ann Surg Treatment Res. 2009;7:306-9.

11. Fanning J, Valea FA. Perioperative bowel management for gynecologic surgery. Am J Obstet Gynecol. 2011;205:309-14.

12. Asao T, Kuwano H, Nakamura JI, Morinaga N, Hirayama I, Cide M. Gum chewing enhances early recovery from postoperative ileus after laparoscopic colectomy. J Am Coll Surg. 2002;195:30-2.

13. Su'a Bu Pollock TT, Lemanu DP, MacCornick AD, Connolly AB, Hill AG. Chewing gum and postoperative ileus in adults: a systemic literature review and meta-analysis. Int J Surg. 2015;14:49-55.

14. Ho YM, Smith SR, Pockneyp P, Lim P, Attia J. A meta-analysis on the effect of the sham feeding following colectomy: should gum chewing be included in enhanced recovery after surgery protocols. Dis Colon Rectum. 2014;57(1):115-26.

15. Keenahan M. Does gum chewing prevent postoperative paralytic ileus? Nurs. 2014;44:1-2.

16. Waldhausen JH, Schirmer BD. The effect of ambulation on recovery from postoperative ileus. Ann Surg. 1990;212:671-7.

17. Nimarta, Singh NV, Shruti, Gupta R. Effectiveness of chewing gum on bowel motility among the patients who have undergone abdominal surgery. Nur Midwifery Res J. 2013;9(3).

Cite this article as: Bhatiyani $\mathrm{B}$, Pandeeswari, Bhasani D, Dhumale S. Effect of chewing gum on the postoperative recovery of gastrointestinal function after gynaecological laparoscopic surgery. Int J Reprod Contracept Obstet Gynecol 2018;7:6447. 